\title{
How people think about distributing aid
}

\author{
Nicole Hassoun ${ }^{\mathrm{a}}$, Emir Malikov ${ }^{\mathrm{b}, \mathrm{c}}$ and Nathan Lubchenco ${ }^{\mathrm{a}}$ \\ aDepartment of Philosophy, SUNY Binghamton, Binghamton, NY, USA; ${ }^{b}$ Department of Economics, St. Lawrence \\ University, Canton, NY, USA; 'Department of Economics, Binghamton University, Binghamton, NY, USA
}

\begin{abstract}
This paper examines how people think about aiding others in a way that can inform both theory and practice. It uses data gathered from Kiva, an online, non-profit organization that allows individuals to aid other individuals around the world, to isolate intuitions that people find broadly compelling. The central result of the paper is that people seem to give more priority to aiding those in greater need, at least below some threshold. That is, the data strongly suggest incorporating both a threshold and a prioritarian principle into the analysis of what principles for aid distribution people accept. This conclusion should be of broad interest to aid practitioners and policy makers. It may also provide important information for political philosophers interested in building, justifying, and criticizing theories about meeting needs using empirical evidence.
\end{abstract}

\section{ARTICLE HISTORY}

Received 7 December 2015

Accepted 5 February 2016

KEYWORDS

Aid; distributive justice; need; poverty

\section{Introduction}

Suppose you had to choose how to lend $\$ 500$ dollars. Would you lend all $\$ 500$ to a woman in Costa Rica for capital to expand her clothing shop? Would you divide it up equally between a man in Uganda to buy an ox for his farm and a woman in Bolivia to buy textbooks for school?

This paper tries to determine how people think about aiding others in a way that can inform both theory and practice. It uses data gathered from Kiva, an online, non-profit organization that allows individuals to aid other individuals, to isolate intuitions that people find broadly compelling. Although Kiva lenders are technically giving loans, the paper takes them to be offering aid because the loans do not bear interest (and are uninsured). This is in line with definitions of aid from international institutions (World Bank Group, 2016). Nevertheless, readers are welcome to substitute a different term throughout since the distinction between loans and other kinds of aid is not what is of interest here. Different norms may be associated with lending money and aiding people in other ways. This is especially likely if Kiva lenders are concerned about getting their money back. So further research on this topic is pressing and important.

This paper also attempts to stay neutral on what people are responding to in aiding others (e.g., lack of resources, opportunities, welfare). To do this, it will use the term 'need' to capture whatever it is that people below some threshold lack. ${ }^{1}$ It will refer to whatever alleviates need or brings someone higher above the threshold as 'aid'. Material goods and utility may be aid in this sense. Alternatively, opportunities might be necessary to alleviate need (Miller, 1999). ${ }^{2}$ Moreover, the paper tries to stay neutral on the appropriate level of the threshold, though it supposes that those seeking loans are below this threshold. 
This paper has several results. The central result of the paper is that lenders seem to give more priority to aiding those in greater need, at least below some threshold. This might not strike some readers as particularly surprising, but consider that people might have chosen to minimize need without considering its distribution or preferred only to help some below a given threshold but not to give priority to helping those who initially had greater need. Alternatively, it could have been the case that people did not just give more priority to helping those below some threshold; people could have also given priority to helping those with greater needs at all levels. Political philosophers have argued for several competing principles for aiding the poor, and it is interesting to see what principles most people actually accept (Miller, 1999).

This paper's results are important for many projects. They can be used to build, justify, and criticize philosophical theories about how people think about meeting need (Brock, 1998). After all, some political philosophers, like David Miller (1999), argue at length that social science and theoretical inquiry are necessarily interdependent. Miller argues that while reflective equilibrium is often narrowly construed as within an individual, it ought to be expanded to include the considered judgments between individuals. He suggests that

Looking at what other people believe about justice, and in particular trying to understand when people disagree and what the grounds of their disagreement are, are integral to the process of deciding which of [one's] ... own beliefs deserve to be taken as 'the fixed points'. (Miller, 1999, p. 56)

Expanding reflective equilibrium to include considered judgments between individuals is particularly important when the beliefs in question are controversial. As Nahmias, Morris, Nadelhoffer, and Turner argue, there is reason to worry about

standard philosophical methodology, whereby philosophers consult their own intuitions from the armchair and assume that they represent ordinary intuitions. While this practice may be appropriate when such an assumption is uncontroversial ... philosophers have conflicting intuitions, intuitions that may well have been influenced by their own well-developed theories. (2006, p. 85)

Consider Derek Parfit's discussion of a case by Thomas Nagel: Nagel imagines that he has two children, one healthy and happy, the other suffering from some painful handicap. Nagel's family could either move to a city where the second could receive special treatment or move to a suburb where the first child would flourish (Parfit, 1997). However, there is disagreement about whether the greater benefit to the first child outweighs the greater needs of the second child. Folk intuitions may help arbitrate these disagreements. At least when political philosophers disagree about controversial intuitions and are attempting to explicate the core commitments of common sense morality, appealing to the beliefs of ordinary people might shift the burden of proof onto those who would deny more widely shared intuitions. This paper's results can be interpreted as providing evidence about the beliefs of ordinary people.

Although this paper's conclusions are primarily descriptive (not normative), its results may help arbitrate some debates about which principles for distributing aid to those in need are correct. In Principles of Social Justice, for instance, Miller relies on evidence about what people believe to argue against the view that we should be indifferent between distributions that simply minimize the amount of need in a situation and those that give strict priority to aiding more needy people at all levels. On the other hand, Gillian Brock (2005) uses such evidence to suggest that people believe it is more important to meet the needs of those below some threshold than those above that threshold. ${ }^{3}$ If we can draw on evidence about what people believe in arguing about what justice requires, this paper's conclusions might buttress some of the theories about how we should meet needs over others.

This paper will proceed as follows. The next section discusses the data Kiva provides. It then sets out several principles for distributing aid according to need. Section 4 presents empirical evidence that people favor some of these principles over others. Section 5 responds to objections to this paper's conclusion that, when making decisions about aiding those in need, Kiva lenders are more concerned about aiding those in countries that are less well off, at least below some income threshold. Finally, this paper considers the theoretical and practical importance of its conclusions. 


\section{Kiva data and question for analysis}

Kiva is a non-profit microfinance organization that allows people to lend small amounts of money to people in need. Microfinance is the umbrella term for providing small-scale financial services to those without traditional access to such services. ${ }^{4}$ Often this takes the form of micro-loans of as little as several hundred dollars.

Kiva lenders do not just donate a sum of money to Kiva to be distributed at Kiva's discretion. Instead, lenders browse the website and choose to lend to a particular individual. ${ }^{5}$ The lender does not receive any interest payments and assumes the risk of default, so the loan is not an investment opportunity. Users can search by region, country, gender, purpose, popularity, and how close the loan is to being fully funded.

Once a specific loan is selected, there is a variety of information available to the potential lender. There is a photo of the individual (or group), a brief biography written by a volunteer for Kiva, and description of the purpose and funding status of the micro-loan. Information about the country of the borrower is available: the average annual income (adjusted for Purchasing Power Parity (PPP)), the currency, and the exchange rate. Further information is available, but it requires clicking some hyperlinks and actively seeking it out. The lenders represented in this dataset are of a wide community, and, assuming their actions are connected with their beliefs, data about their actions will provide some information about what people believe. ${ }^{6}$ Because of Kiva's success and willingness to share its data online, there is a large and interesting data set of over 30,000 loans available to be analyzed (from April 2006 to February 2008). ${ }^{7}$ The lenders come from nearly 200 countries and are of various ages and socio-economic statuses. ${ }^{8}$

This paper uses Kiva data to consider how people think about distributing aid to people in need, though doing so requires several (potentially controversial) assumptions. First, the paper assumes that the amount of time it takes for a loan to get funded on Kiva, ceteris paribus, is a reasonable proxy for the level of priority people place on distributing aid to that individual. ${ }^{9}$ So if people care more about helping someone in Belize than helping someone in Mexico, then (other things being equal) the loan to a person in Belize will be funded more quickly. Second, the paper assumes that the per capita income of the borrower's country is a reasonable proxy for how much that individual needs. ${ }^{10}$ That is, this paper assumes there is some connection between how much money people have (on average) in a country and how much most Kiva borrowers in that country need. This is compatible with the fact that some people need things that money cannot buy and some have unmet needs despite having a lot of money. ${ }^{11}$ The paper's aim, then, is to determine which of several principles for distributing aid to those in need (if any) people might accept.

\section{Principles for distributing aid}

A principle governing the distribution of aid to those in need (henceforth, "a principle for distributing aid") is neither a comprehensive ethical theory nor a theory of how political institutions should act. ${ }^{12}$ A principle for distributing aid is instead, ceteris paribus, an account of how individuals should aid those in need. What follows will focus exclusively on principles for distributing aid.

The first principle for distributing aid this paper considers, distribution insensitivity, serves as its null hypothesis. When people are distribution insensitive, they are no more likely to give to those in greater need than to those in less need (see figure 1). The paper assumes that people are distribution insensitive when there is no relationship between funding time and per capita income. If this hypothesis can be rejected, there is some relationship between the variables of interest.

The second principle this paper considers is a prioritarian principle for distributing aid. This is really a category of principles. Those who accept a prioritarian principle for distributing aid will give preference to aiding people with greater need over aiding those with less need (Parfit, 1997; see also Hassoun, 2009). The moral value of providing a unit of aid to a person in need is greater the more that person needs it. The value of aiding a person at any given level of need is determined by a prioritarian weighting function. Figure 2 illustrates one prioritarian principle derived from one such function. ${ }^{13}$ 


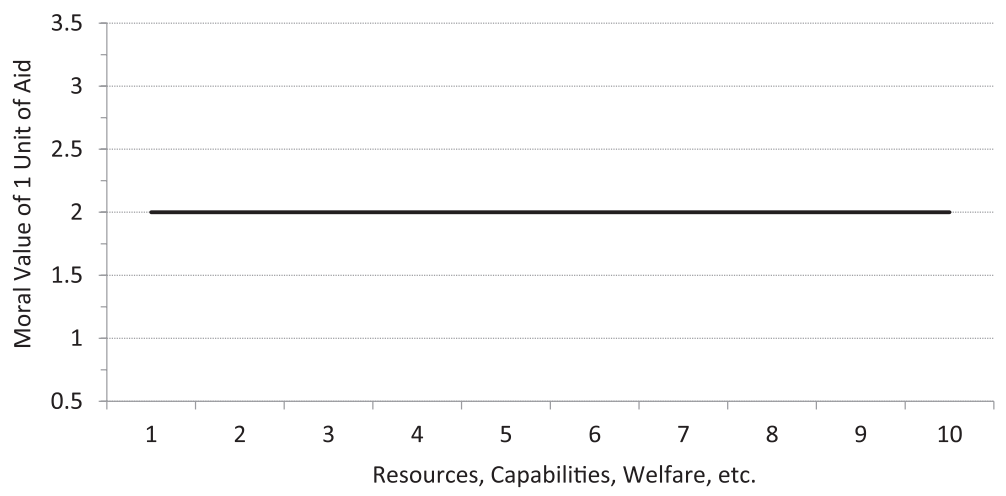

Figure 1. Graphical representation of distribution insensitivity.

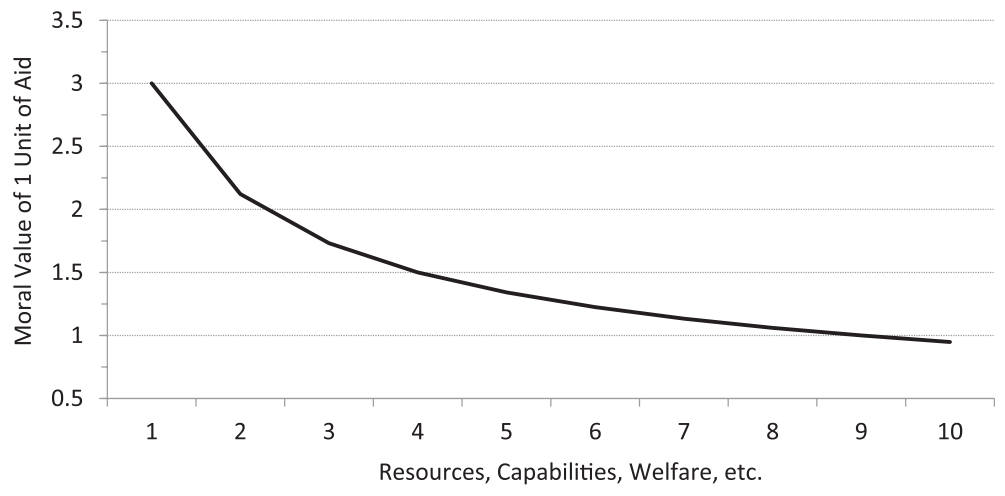

Figure 2. Graphical representation of prioritarian principle.

This figure shows that it is better to provide a unit of aid to a person with, say, 1 unit of resources, capabilities, welfare, or whatnot than to a person with 4 units. The moral value (priority) of aiding is higher in the former instance where the need is greater. (Giving a single unit of aid to someone with 1 rather than 4 units generates 3 versus 1.5 units of moral value in the figure above.) It is also preferable to aid an individual with 4 units of resources over the one with, say, 6 units. (Giving a single unit of aid to someone with 4 rather than 6 units generates 1.5 versus 1.25 units of moral value.)

We group the third category of principles under consideration as threshold principles for distributing aid. Like prioritarian principles for distributing aid, there are many possible threshold principles (with thresholds at different levels). ${ }^{14}$ We take as the central claim of a threshold principle for distributing aid that it is appropriate to give preference to those below some threshold and that one should treat those below that threshold equally and those above that threshold equally. ${ }^{15}$ The graphical representation of one such threshold principle is given in figure 3.

Here the threshold is at 4 units of resources. So aiding someone with 3 units has higher moral value and thus greater priority than aiding someone with 5 units. (Giving a single unit of aid to someone with 3 rather than 5 units generates 2.5 versus 1.5 units of moral value in the figure above.) Aiding someone with 1 unit would not, however, have priority over aiding someone who had 3 units. Similarly, aiding someone with 5 units would have no priority over aiding someone with 10 units. The motivating idea behind the threshold principle is that once people have enough, it is no longer appropriate to give preference to aiding those who have fewer resources.

The final category of principles this paper considers might be called p-threshold principles for distributing aid. P-threshold principles combine elements of prioritarian principles for distributing 


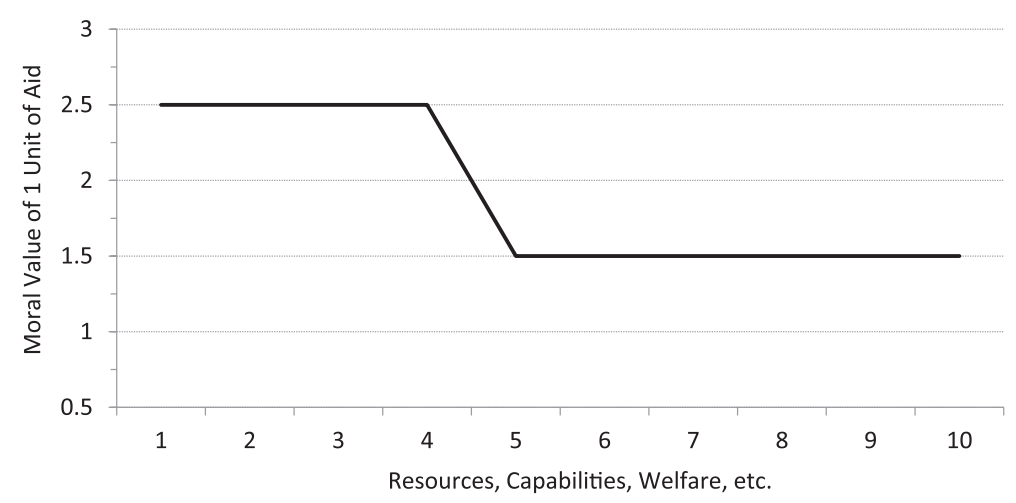

Figure 3. Graphical representation of threshold principle.

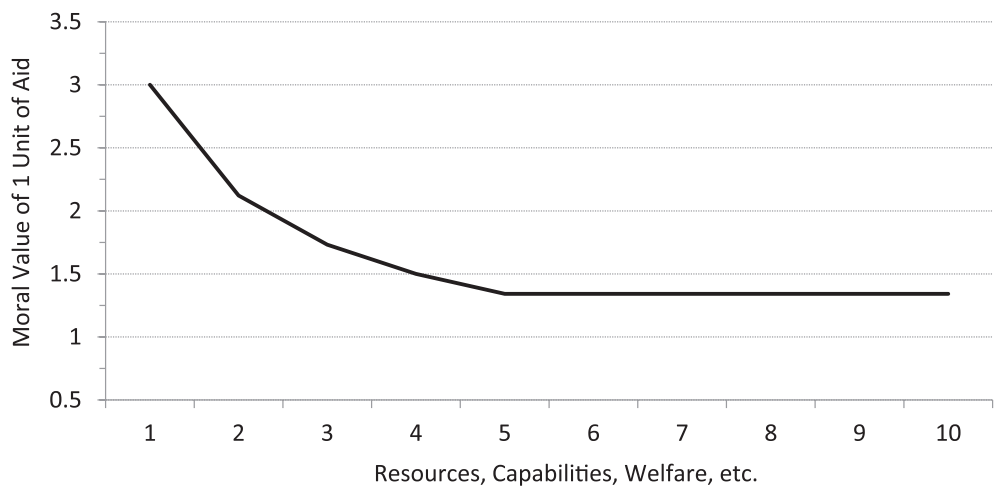

Figure 4. Graphical representation of $p$-threshold principle.

aid below some threshold of resources with a commitment to treating all those above some threshold equally. On p-threshold principles for distributing aid, it is more important to aid those people who have fewer resources below a threshold. Aiding people who have virtually nothing may be more important than aiding those who are struggling but still getting by, for instance, even though it is equally important to aid those above the threshold. Like prioritarian and threshold principles for distributing aid, there are many possible p-threshold principles. They all include a prioritarian weighting function up until some threshold after which people are treated equally. See figure 4 for a graphical representation of a p-threshold principle, where the threshold is arbitrarily (for illustration purposes) assumed to be 5 units of resources.

Here giving a single unit of aid to someone who has only 1 unit of resources is better than giving it to someone who has 5 units of resources. (The former action yields 3 units of moral value as opposed to 1.4 units of moral value.) However, it is not better to help someone who has 5 units of resources as opposed to 10 units. (Both actions yield 1.4 units of moral value.)

\section{Empirical results}

This section presents the results of three regressions and explains the empirical strategy we employ in the regression analysis. Regression analysis is used to estimate the relationship between two or more variables-here, funding time and per capita income. ${ }^{16}$ The regression looks at how the independent variable (per capita income) influences the dependent variable of interest (funding time), holding all other determinants of the latter constant. As noted in section 2, we think of the loan funding time as a 
reasonable proxy for the level of priority people place on distributing aid to those in need. We take the per capita income of a borrower's country as a proxy for the degree of a borrower's need. Using regression analysis, we attempt to investigate the nature of the relationship between these two factors (provided there is any) and then reconcile the results with the predictions of the four principles for distributing aid outlined earlier in section 3 . We believe the results of the analysis provide evidence regarding which principles for distributing aid Kiva lenders accept. Technical details are relegated to notes and the appendix.

In examining how per capita income affects funding time for Kiva loans, we also control for other potential sources of variation in the loan funding time. ${ }^{17}$ In particular, we control for the log of the loan amount, the uses of the loan (retail, agriculture, services, etc.), a borrower's gender, the year and the month the loan was funded, regional variables for Africa, Latin America, and Asia, and the United States, military involvement in a borrower's country. Controlling for these characteristics of the loan allows us to identify the ceteris paribus effect (that is, the partial effect) of the per capita income on the loan funding time across all the loans. The rationale for including these controls is as follows. Loan size is an important variable to investigate. Everything being equal, a larger loan should take longer to fund. It is important to account for the uses of a loan since Kiva lenders might be biased toward funding certain types of loans. One might hypothesize that a lender may be more inclined to fund a loan that will be spent on purchasing a cow than to fund a loan for expanding a retail clothing store, for instance. Thus, one might expect the latter loan to take longer to get funded. Since microfinance is often targeted at women, it is important to account for any potential gender differential in how quickly the loan gets funded. Months were included to control for seasonal variation, particularly around December, and years were included to account for Kiva's increasing popularity. It makes sense to compare June loans to June loans and not to December loans and likewise to compare loans made in 2008 to other loans in 2008 rather than in 2006, when there was substantially less website traffic. These controls help ensure that the association between per capita income and funding time is not due to other factors.

We consider three different regression specifications for four different models (see the appendix for details). These are designed in an attempt to capture the relationship between the loan funding time and the per capita income in a way that will shed light on the underlying principle for distributing aid that people seem to follow (if any). However, to conserve space, we report the results for the last model only - this is the model, among the four, that best fits the data (see appendix). We now proceed to the regression results for this model under three different specifications.

\subsection{Specification I}

Since we do not have prior knowledge of the relationship between the loan funding time and the per capita income, we chose a simple specification to examine whether there is any statistically significant relation between the two variables. We thus start by setting the loan funding time to be a function of the income per capita (measured in thousands of PPP-adjusted U.S. dollars). We also include the set of controls listed in the beginning of this section. To account for the possibility that the relationship between the loan funding time and per capita income is not linear (i.e., cannot be depicted via a straight line), we also include the square of per capita income in the regression. ${ }^{18}$ This is a standard procedure for capturing potential non-linearities in the empirical literature.

The coefficient of the per capita income (jointly with its square term) is statistically significant at the $1 \%$ significance level (see the appendix for regression results), where the latter represents a rather small $1 \%$ probability of our mistakenly rejecting the true null hypothesis of a zero effect of the per capita income on the loan funding time. Hence, probabilistically we can be very confident that the per capita income has a non-zero effect on the loan funding time. This suggests that Kiva lenders are indeed distribution sensitive and that they do consider how much need a potential borrower has relative to others when making their decisions about funding loans. Figure 5 illustrates this. ${ }^{19}$ It tells us that, ceteris paribus, it takes almost half as much time for a borrower from a country with virtually zero income to get a loan funded as it would take for someone from a relatively rich country of $\$ 10,000$ per capita. ${ }^{20}$ To give a specific example, a borrower from Democratic Republic of Congo, the poorest 


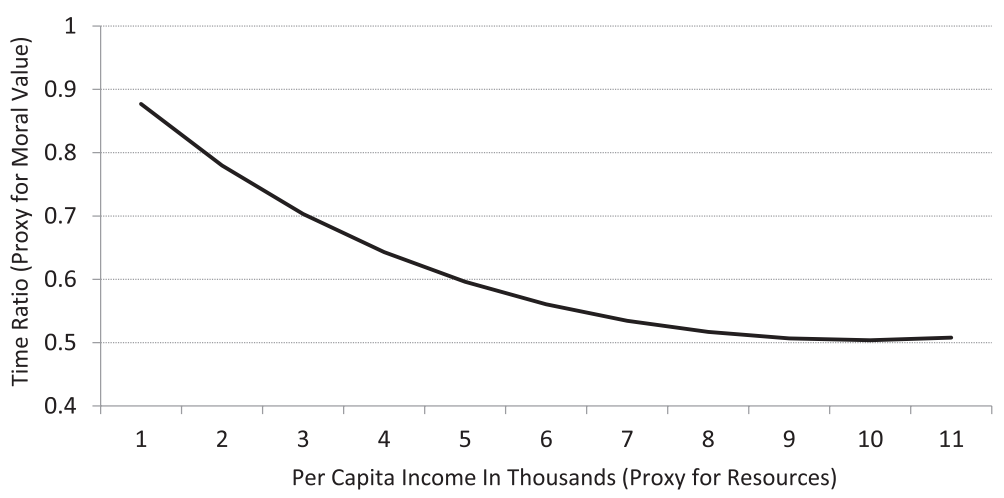

Figure 5. Loan funding time ratio (Specification I).

country in our sample ( $\$ 119$ per capita) is predicted to get a loan funded 1.94 times quicker than a borrower from Bulgaria, the second richest country in our sample ( $\$ 10,840$ per capita).

Figure 5 suggests two conclusions. First, people do seem to be distribution sensitive: had they not been, the loan funding time would not have changed with per capita income, and figure 5 would have plotted a straight horizontal line (as in figure 1). Second, there is some indication of a threshold beyond which Kiva lenders stop prioritizing loans to borrowers with greater need (as captured by the country's income per capita). Starting at the income level of about $\$ 9,000$ per capita, the borrower's relative need seems to have virtually no effect on the loan funding time. They also seem to give priority to aiding those with greater need below this threshold. This is in line with the p-threshold principle for distributing aid: Kiva lenders act according to the prioritarian principle when distributing aid to relatively poor borrowers and are distribution insensitive above the approximately $\$ 9,000$ per capita income threshold. ${ }^{21}$ Indeed, the relationship depicted in figure 5 falls into the family of p-threshold principles graphically presented in figure 4 .

\subsection{Specification II}

One might worry that the shape of a graph above may be due to the chosen specification. In particular, recall that under Specification I we have included a square term of the per capita income in the regression, which may be the primary source of the apparent parabolic relationship that we observe in figure 5.

To address this potential problem, we break down the data into four income groups. ${ }^{22}$ After running the regression again, we find that the observed pattern still indicates that the Kiva lenders are distribution sensitive. However, it now suggests that a threshold, rather than p-threshold, principle governs people's lending behavior (see figure 6). ${ }^{23}$ While figure 6 does produce a relationship like the one plotted in figure 3 , it might seem that the results do not perfectly match the threshold principle. This is especially evident for the third and fourth income groups, which appear to be somewhat different from one another. This difference, however, is not statistically significant at the $1 \%$ significance level, leading us to conclude that there is no difference "with $99 \%$ confidence". ${ }^{24}$ It is noteworthy that, although the two Specifications (I and II) lead to different conclusions, a simple statistical procedure tells us that the first specification fits the data best. ${ }^{25}$ Reflecting on the shapes of the graphs, however, it is not clear that either specification is the correct one.

\subsection{Specification III}

The shape of the graph in figure 6 suggests that it is worth considering a different specification of the regression which would allow for the apparent relationship between the per capita income and funding 


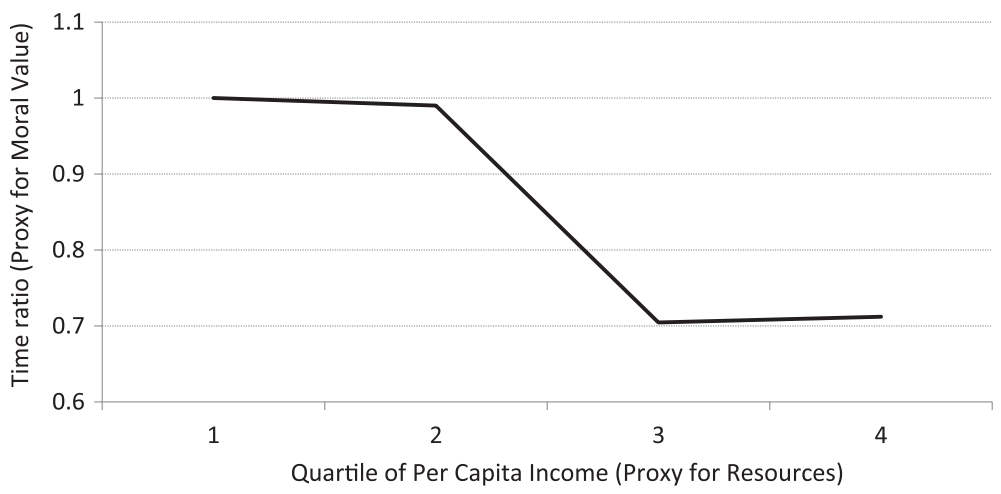

Figure 6. Loan funding time ratio (Specification II).

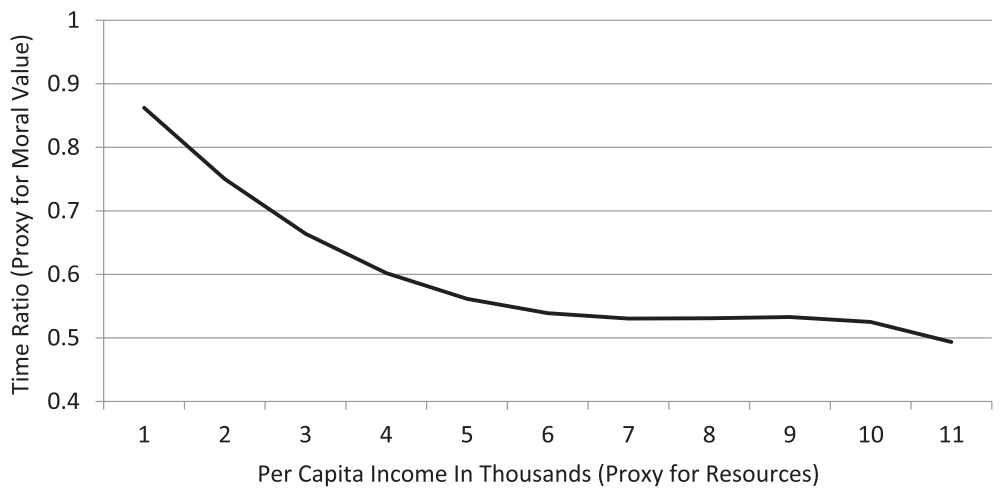

Figure 7. Loan funding time ratio (Specification III).

time to come out more clearly. ${ }^{26}$ In particular, we next consider a specification that includes the cube and fifth-power of the per capita income in the regression. ${ }^{27}$

Under specification III, we get the results depicted in figure $7 .{ }^{28}$ First, the figure does not confirm a threshold principle as in the case of Specification II. Instead, the evidence yet again suggests prevalence of the p-threshold principle. Unlike under specification I, the plateau is now relatively longer, indicating a lower threshold (in terms of income) of around $\$ 7,000$ per capita. This specification is also preferable to the two others based on statistical model selection procedures: it fits the data better than all other alternatives. ${ }^{29}$

The only caveat with this model is the anomalous downtick at the income of $\$ 11,000$ per capita. There are two countries in that range of income in our sample: Mexico and Bulgaria. This unintuitive prediction of the estimated model warrants an explanation. First, the two countries are the richest in our sample. The next richest country is Ukraine, with an income of only $\$ 8,000$ per capita. This may support treating both Mexico and Bulgaria as outliers in our sample and taking predictions for that range of income to be unreliable. Second, one can hypothesize that loans from Mexico and Bulgaria take longer to get funded than they should for some other (unknown) reason. Perhaps lenders, who are mostly from the United States, are biased against giving aid to Mexicans and believe that Bulgaria is richer than it is, so loans from these countries take more time to get funded. Controlling for both countries in the regression does not, however, eliminate the peculiar behavior of the predicted funding time for that income range. So we are more inclined to accept the first explanation-the two countries are outliers in our sample, especially given that the dataset contains a wide gap in the range of $\$ 8,000$ to $\$ 11,000$ per capita. Thus, further research using a richer dataset is warranted. 
Table 1. Log-logistic regression. Reported are the estimates of the coefficients with robust standard errors in parentheses. The robust standard errors are corrected for heteroskedasticity, which is defined as the violation of the constant-variance assumption about the error term in the regression equation that results in incorrect estimates of standard errors if not accounted for. The results for control variables are omitted to conserve space, but available upon request.

\begin{tabular}{|c|c|c|c|}
\hline & (I) & (II) & (III) \\
\hline $\begin{array}{l}\text { Per capita income of borrower's country (in thousands of PPP-adjusted } \\
\text { US dollars) }\end{array}$ & $\begin{array}{l}0.138^{*} \\
(0.007)\end{array}$ & & $\begin{array}{l}0.150^{*} \\
(0.010)\end{array}$ \\
\hline Per capita income $\wedge 2$ & $\begin{array}{c}-0.007^{*} \\
(0.001)\end{array}$ & & \\
\hline Per capita income $\wedge 3$ & & & $\begin{array}{c}-0.002^{*} \\
(0.000)\end{array}$ \\
\hline Per capita income $\wedge 5\left(\times 10^{-3}\right)$ & & & $\begin{array}{l}0.007^{*} \\
(0.001)\end{array}$ \\
\hline Bottom quartile (by per capita income) & & $\begin{array}{c}-0.339^{*} \\
(0.020)\end{array}$ & \\
\hline Second quartile & & $\begin{array}{c}-0.329^{*} \\
(0.017)\end{array}$ & \\
\hline Third quartile & & $\begin{array}{c}0.011 \\
(0.016)\end{array}$ & \\
\hline No. of Obs & 33,186 & 33,186 & 33,186 \\
\hline Log-likelihood & $-44,965.59$ & $-44,999.78$ & $-44,955.03$ \\
\hline AIC & $90,003.17$ & $90,073.56$ & $89,984.06$ \\
\hline
\end{tabular}

*Significant at the $1 \%$ level.

**Significant at the $5 \%$ level.

\subsection{Summary of regression results}

To conclude, the data show strong evidence that people indeed consider relative need when distributing aid. Distribution insensitivity is firmly rejected by all three specifications we consider in the paper. Moreover, the results also suggest that most lenders seem to accept a p-threshold principle for distributing aid. However, one needs to keep in mind that our results do not imply that every single Kiva lender follows a p-threshold principle; they rather indicate that lenders accept this principle on average. In fact, our sample may be a mix of different kinds of people: those who strictly follow either prioritarian principles or threshold principles and those who accept a combination of these principles, such as a p-threshold principle. The identification of principles for distributing aid relevant to every lender individually requires the use of more sophisticated statistical methods. We leave it for further research. Nevertheless, if one still has reservations about accepting our findings in favor of the p-threshold principle due to the issues discussed above, the data nevertheless strongly confirm incorporating both a threshold and a prioritarian principle into the analysis of what principles for aid distribution lenders accept (on average).

\section{Objections and responses}

There are many ways that our results might be biased. Consider, for instance, how our study is sensitive to the order in which the loans are posted..$^{30}$ If people are more likely to fund loans that are posted earlier and Kiva gave priority to those most in need in posting loans, then that might make it seem like people care more for aiding the more needy than they actually do.

Because the Kiva data set is limited, it is impossible to test for all potential sources of bias here. There is, for instance, no information about a loan's relative location on the website. Since, however, a quick look at the website suggests no obvious pattern for posting loans, and since lenders can also sort the loans in several different ways, this worry may not be very pressing. In the future, however, researchers might work with Kiva to secure more data and test for potential sources of bias. Mousetracking technology may also help researchers secure information about what people are attending to in making loans. If someone discovers an actual source of bias in our study, this would provide good reason to reconsider our conclusions. 
A different worry is that the regression results we report are subject to sample selection bias. People who use Kiva are significantly different from those who do not lend on Kiva. They are more likely to be conscientious about helping those in need than the average person. They are self-selected, or selected by someone they know if they are given a gift certificate. Therefore, the sample is unlikely to be representative of the population as a whole. Additionally, in order to register on the website, Kiva lenders must have access to the internet, which limits the sample to those of relatively higher socio-economic status.

While these sources of sample selection bias can potentially cause problems, looking at the data sample we have can, nevertheless, be very revealing, given the research question we posit. It might sometimes be appropriate to weight the intuitions of those who care about and are able to aid the needy more heavily than the intuitions of others. These people may, on average, be better educated, more compassionate, or may have spent more time reflecting on issues of need. In the same way that physicists may have more interesting and useful intuitions about cosmology, it is reasonable to hold that more reflective folk intuitions may be more informative for some purposes. ${ }^{31}$ There are, at least, many ways in which the Kiva sample is significantly larger and more diverse than almost any existing sample in experimental philosophy. It is not just a small sample of undergraduates' intuitions. It contains data from a great number of lenders from almost every country in the world (many of these people received gift certificates and may not otherwise have navigated to the site). Although the sample is biased in some ways, requiring our conclusions to be appropriately qualified, it may not be biased in a problematic way.

A different worry is that lenders may not be thinking about principles for distributing aid when selecting which projects to fund. If so, it is unclear that their actions tell us anything about their underlying intuitions. One might suggest limiting the study to Kiva lenders who carefully consider the moral implications of their lending choices. The fact that some lenders are probably not thinking about how to meet need when giving loans on Kiva may not be problematic. It biases this study's results towards showing no pattern, but we find clear patterns (assuming no unintentional bias). Second, people might follow a principle for distributing aid even if they do not consciously consider it when making their decisions. Third, there is, in any case, no way to restrict our sample to those who are trying to apply a principle for distributing aid. Finally, even if we could rely upon lenders who carefully consider the moral implications of their lending choices, it may still be unadvisable to do so since it would limit our data set and make it less representative.

In short, while there may be some concerns that this study has not been able to address, it nevertheless provides some reason to believe that, on average, Kiva lenders are making loans that are consistent with a p-threshold principle for distributing aid.

\section{Conclusion}

This project has used empirical data to consider how people think about distributing aid. Specifically, we examined historical data in which people made decisions about distributing aid using their own money. This paper attempts to determine what principles for distributing aid people embrace. Its results suggest that Kiva lenders, in general, use a p-threshold principle. ${ }^{32}$ In any case, the data strongly reject the null hypothesis of distribution insensitivity.

This conclusion is important for theory and practice. It should be of broad interest to empirically informed political philosophers in making and arbitrating between theories (Miller, 1999). For political philosophers that give any weight to the common sense morality of ordinary people, this paper provides some evidence for what the common sense view is in regard to meeting needs. The evidence this paper provides is thus useful for building, justifying, and criticizing theories about meeting needs-we have seen, for instance, that it provides reason to reject distribution insensitivity and casts doubt on prioritarian and threshold principles. ${ }^{33}$ If these data help researchers build broadly compelling arguments for aiding the needy in some ways over others, it could also be pragmatically useful. 
Moreover, this paper's results are important for other projects. Judith Lichtenberg (2004) argues, for instance, that in order to actually relieve poverty, it is important to understand human psychology. She thinks that it is necessary to bridge the gap between what people report that they believe and how they act. Toward this end, she asks, "What is the relationship between reason and motivation: does believing that one ought to do X entail that one is moved to do X?" (Lichtenberg, 2004, p. 75). There already exists some evidence about the former. ${ }^{34}$ This paper contributes evidence about the latter (also see Hassoun, 2009)

Finally, this paper suggests two avenues for future research, the first empirical and the second theoretical. Further empirical work might proceed by considering other proxies for need, including the number of poor people in each country, the proportion of poor people, literacy rates, infant mortality rates, life expectancy, or some weighted average of the above. The strong influence of U.S. military involvement on the funding time of loans suggests investigating other factors such as natural disasters, epidemics or political turmoil that influence how people perceive the needs of others. Further work could be done along these lines by using the earthquake in Haiti as a natural experiment. Using a more recent Kiva dataset would allow loans before the earthquake to be compared to those after the earthquake. The difference in the funding time would represent how Kiva lenders perceive the need of those who have suffered a natural disaster. Similar, more detailed investigations could be conducted on many countries for many reasons: the number of times poverty in a country is mentioned in the news media could be an interesting independent variable for further study, since it might be a reasonable proxy for perception of need. Future theoretical research is necessary to explore all the ways this paper's results can help arbitrate between theories about how we should distribute according to need. This study also encourages methodological reflection on which kinds of empirically based political theories are useful for establishing different hypotheses.

\section{Appendix: Regression analysis}

Since the funding time of the loan is a duration variable, the naturally applicable regression approach is the method of duration analysis designed to tackle transition data (this is also known as survival analysis in biological and biomedical applications or reliability analysis in engineering). In the case of Kiva lending data, the "transition" we observe is the process of a loan getting funded, in other words, transitioning from the unfunded to the funded state. The loan funding time constitutes the "duration" of the unfunded state. The reason we use special regression methods here is that funding time is a non-negative variable. That is, the time it takes to fund a loan will always be some positive amount of time. This makes traditional methods like Ordinary Least Squares (OLS) unsuitable for this analysis: OLS hinges on the assumption that the variable on the left-hand side of a regression equation has a real codomain, so funding times would have to be both positive and negative. ${ }^{35}$

In particular, we estimate a hazard model, where "hazard" (or "hazard rate") stands for the instantaneous probability of completing the transition from one state to the other, conditional on it remaining incomplete until this very instant. ${ }^{36}$ Applied to our particular study, the definition of the hazard rate would be the probability of getting the loan funded on, say, the tenth day, conditional on having it still unfunded by the tenth day. The regression models this probability as a function of the explanatory (independent) variables to identify how these variables affect the hazard.

While there are many ways of looking at the results produced by a hazard model, in our case it is most natural and intuitive to analyze the data by looking at the predicted total time until the loan is funded (compared to some reference group) ${ }^{37}$ Recall that the assumption is that the loan funding time indicates the priority given to loans by lenders. The paper seeks to investigate how these priorities change with the per capita income of a borrower's country. Thus, all the conclusions are drawn based on the results reported in terms of the loan funding time.

In this paper we consider four parametric hazard models that are built upon different distributional assumptions about the duration variable (the loan funding time). That is, we consider whether the loan funding time follows exponential, Weibull, log-normal, or log-logistic distributions. We chose to look 
at these four different distributions because they differ in the duration dependence (i.e., how hazard rate changes with the time) that each of them implies. In particular, while exponential distribution implies a constant hazard rate that does not change over time (no duration dependence), Weibull distribution can yield a hazard rate that can be either monotonically increasing (positive duration dependence) or monotonically decreasing over time (negative duration dependence). The hazard rate of a log-normally distributed variable is not monotonic: it first rises and then falls with the passage of time. Log-logistic distribution is, however, the most flexible of the four-it can imply either a monotonically decreasing hazard or one that behaves similarly to the hazard of the log-normal distribution (inverted U-shape). Since all of the models are non-linear in parameters, ${ }^{38}$ they are estimated via the Maximum Likelihood method, the underlying principle of which is, given the distributional assumption, to find values of the unknown parameters that will maximize the probability of observing the actual sample data. The latter is done by maximizing the log-likelihood function (the joint probability function for the sample) in the unknown parameters. ${ }^{39}$

Considering such a wide range of hazard models is warranted by the fact that we lack a priori knowledge of the nature of duration dependence-none of the proposed principles for distributing aid tells us what to expect about the behavior of the hazard rate over time. We thus prefer that the data tell us which of the models fits the data best.

Discriminating between the exponential and Weibull models is fairly simple. The comparison of the two models boils down to a test of the hypothesis that the Weibull shape parameter is equal to unity. ${ }^{40}$ The exponential model is thus rejected in favor of the Weibull model if the shape parameter is statistically significantly different from unity. In order to compare the remaining three models (Weibull, log-normal, and log-logistic) a common approach is to use the Akaike Information Criterion (AIC), a measure of the relative goodness of fit of the model. The idea behind any goodness-of-fit measure is to see how well a model matches the data. One of the ways to measure fit is in terms of the maximized value of the log-likelihood function, that is, the log-likelihood function evaluated at the parameter estimates obtained by maximizing the former. In this case, the higher the maximized value is, the more likely one is to observe the data sample, and the better the data fits the model. However, the less parsimonious models, those with more parameters, tend to fit data better, which nevertheless comes at the expense of a loss of degrees of freedom. ${ }^{41}$ The AIC accounts for this tradeoff: it penalizes adding extra parameters to a model and only counts them as an improvement if the increase in fit is sufficient to overcome the loss of parsimony. The model with the lowest AIC is standardly considered the best among given alternatives.

We test three different regression specifications (described in the main body of the paper) for each of these four hazard models. However, to conserve space, this paper reports the results for log-logistic model only-this is the model, among the four, that best fits the data. Under each of the three regression specifications, the exponential hazard model is rejected in favor of the Weibull model at the conventional 5\% significance level. However, based on the AIC criterion, it is the log-logistic model that beats the two other alternatives (Weibull and log-normal) under all three regression specifications. See Table 1 for the output of the log-logistic model. ${ }^{42}$

\section{Notes}

1. On the proper basis for poverty measurement, see Nussbaum (2000), Pogge (2004), and Sen (1997). On different philosophical conceptions of basic needs, see Braybrooke (1987) and Brock (1998).

2. Talk about needs and aid does not presuppose that any particular way of distributing aid (in the relevant broad sense) is best. It might, for instance, alleviate just as much need to give 10 children a year of schooling as to inoculate a single child against measles.

3. Brock (1998) is committed to the relevance of empirical evidence about ordinary individuals' intuitions.

4. This does not mean that users of microfinance do not have access to credit, in fact they often do have access to credit, but it is often either extremely expensive, unreliable, or both (Rosenberg, 2010).

5. Note that as Kiva scaled up in size, it began dispersing loans before they were funded on the site, creating a significant controversy. For more information, see Ogden (2009). 
6. Despite being widely representative in this way, there are some important ways in which the sample may be biased. Access to the internet may bias the selection according to socio-economic status, and the lenders are self-selected.

7. We are grateful to Joseph Ramsey for assistance in gathering the data.

8. Currently, 196 countries are represented by Kiva lenders. This is likely a marked increase from the older snapshot of data considered here, but even this older sample contains a globally diverse set of lenders. The majority, however, are from the United States. The lenders include everyone from students to software engineers to retired people.

9. The purpose of the ceteris paribus clause is to prevent a simplistic interpretation of how quickly a loan gets funded. For example, it might be objected that obviously bigger loans will take longer to fund, but by controlling for the size on the loan in the regression specification, this worry is mitigated. It is also worth noting that virtually all loans on Kiva eventually get funded, so comparing which loans get funded is not productive.

10. Country incomes are adjusted for purchasing power parity to capture the currencies' purchasing power. PPP measures attempt to equalize rates of currency conversion by accounting for different price levels across countries. One Euro may be worth 1.4 US Dollars, but if goods cost less in the United States, then the purchasing power of the dollar may be higher than the currency exchange rate would suggest. For more information, see www.oecd.org/std/prices-ppp.

11. This paper does not provide an analysis of what constitutes need. It assumes that it is reasonable to talk about how much people need in the absence of agreement on what exactly constitutes need. It also assumes that most people can usually recognize need when they see it and may be motivated to respond to need by providing aid.

12. So, for instance, accepting a prioritarian principle for distributing aid (described below) may not commit one to a completely prioritarian theory of justice. On prioritarianism in other domains, see Parfit (1997).

13. The weighting function must be strictly decreasing and strictly convex in well-being, resources, welfare or whatnot, as the one plotted in figure 2. For a detailed discussion of the prioritarian weighting and value functions, see Lumer (2005). Distinguishing a particular prioritarian weighting function is likely too great a task for this data set. However, it is possible to establish that people are accepting one of a class of prioritarian principles without knowing which particular one they accept. For a technical discussion, see Brown (2005).

14. One possible basis for threshold principles is sufficientarianism. There is significant debate in the philosophical literature about the proper ground and limits of different principles for distributing aid, including sufficiency principles. See Crisp (2003a, 2003b) and Frankfurt (1987).

15. Those who embrace sufficiency theories about what justice or morality requires do not have to embrace a threshold principle for distributing aid, though most will do so. Furthermore, committing to a threshold is not necessary for specifying the aim of their theory. They may believe that other principles will better contribute to achieving sufficiency (just like utilitarians might embrace prohibitions against murder or redistributing organs because they believe doing so will maximize utility). Consider, for instance, sufficiency theorists who only maintain that we should treat all those above some threshold of need equally. These sufficiency theorists can accept some kind of prioritarianism below the need threshold-what we will call a p-threshold principle for distributing aid. On sufficiency theories in ethics, see Frankfurt (1997).

16. If $t$ is funding time and $y$ is per capita income, the basic form of the regression is a linear equation that specifies a linear relationship between $t$ and $y: t=\beta_{1}+\beta_{2} y+\epsilon$, where $\beta$ 's are intercept and slope coefficients and $\epsilon$ is an identically and independently distributed random error. Provided that the above relationship is correctly specified (i.e., that it is indeed of linear form), using data on the loan funding time and per capita income, one can estimate both intercept and slope coefficients that are the sample estimates of the true (unknown) parameters. The estimation of the parameters is of interest for their valuable interpretation: in our particular case, if the borrower comes from the country whose per capita income is a thousand dollars greater, ceteris paribus, it will take $\beta_{2}$ times 1,000 units of time longer (or less) to get her loan funded. Also, knowing the estimates of the parameters enables us to predict, on average, the loan funding time for any known per capita income. For a good introduction to regression analysis, see Wooldridge (2008).

17. We control for those by including respective variables in the regression.

18. A common example of a non-linear relationship is between earnings and age. While earnings always increase with age, the increase tends to be much larger for young ages than for ages close to retirement. Since a straight line cannot be drawn to indicate the relationship, it is a non-linear relationship. We also consider including the cube of the per capita income. The results are not qualitatively different from the ones presented in the paper.

19. See the appendix for an explanation of the models. Note that following a convention in duration analysis, we calculate loan funding time ratios as a function of an explanatory variable of interest, namely per capita income in a borrower's country. In particular, we estimate the predicted ratios of loan funding time for a borrower who comes from a country with zero per capita income (i.e., with the greatest need) over the funding time evaluated at a given per capita income. The choice of the "zero per capita income" reference is purely due to technical convenience. Any other reference point could have been chosen-the results would be qualitatively unchanged. In fact, a "zero per capita income" reference is quite sensible, given our data sample: the Democratic Republic of Congo's per capita income is virtually zero (\$119). Figure 5 plots these time ratios. 
20. The time ratio, defined in the previous footnote, equals 0.5 .

21. Note that figure 5 plots a decreasing, convex curve up until the $\$ 9,000$ threshold, which is consistent with the properties of the prioritarian weighting function discussed in footnote 13. The curve becomes a straight horizontal line here, consistent with threshold principles for distributing aid.

22. This mitigates the potential "smoothing-out" effect of having the per capita income enter the regression as a continuous variable (as in Specification I). More precisely, we now let the loan funding time be a function of per capita income defined as a discrete variable. In particular, we construct indicator (dummy) variables corresponding to quartiles of the distribution of per capita income and let them enter the regression equation. Such indicator variables are usually defined for categorical (descriptive, non-numerical) variables such as gender and country. For instance, to control for gender effects in our regression analysis, we let the equation include the Gender dummy variable defined in the following fashion: Gender $=1$ if a loan is asked for by a female, and $=0$ otherwise. A regression with per capita income defined as a discrete variable, rather than as a continuous variable, is capable of capturing potential non-continuous jumps in the relationship between loan funding time and income (such as a jump in moral value in the case of a threshold principle, as depicted in figure 3). The latter would be impossible if one uses a continuous variable which will, by definition, smooth out a potentially discontinuous relationship.

23. The figure reports the time ratios, where the bottom quartile is chosen to be a reference group (the choice of a reference group is arbitrary and does not change the results qualitatively). Of course, the relationship between per capita income and funding time is no longer represented by a smooth curve as when continuous variables were used under Specification I.

24. The p-value of the Wald test of the two parameters being equal is 0.5081 , leading us to accept the null.

25. Based on the comparison of the AIC criteria explained in Appendix.

26. The graph resembles "one minus" a generic cumulative distribution function. The cumulative distribution function describes the probability of a random variable $X$ taking a value less than or equal to a particular value $x$, i.e., $\operatorname{Pr}[X \leq x]$.

27. This is inspired by a polynomial approximation of a standard normal distribution as suggested by Zogheib and Hlynka (2009).

28. The figure plots the loan funding time ratio with "zero per capita income" country being used as a reference. Also see footnote 19.

29. Using the AIC information criterion (see table 1 in the appendix).

30. Order effects are also discussed in Swain, Alexander, and Weinberg (2008).

31. See Machery and Stich (in press), Schwitzgebel and Cushman (2012), and Weinberg, Gonnerman, Buckner, and Alexander (2010).

32. Other empirical work also suggests that people endorse a threshold (Brock, 2005).

33. Miller (1999) considers several principles for distributing according to need in Principles of Social Justice, and one might expect some utilitarians, prioritarians, and sufficiency theorists to accept distribution insensitive, prioritarian, and threshold principles for distribution respectively. At least this result poses a question to these theorists about why they do not endorse what seem to be the most straightforward applications of their theories (if they do not).

34. For a brief review of early work on this topic by psychologists, see Miller (1999). Also see Brock (2005).

35. Another concern regarding the analysis of duration data is censoring. The latter occurs when transitions are incompletely observed, that is, when transitions take place either before (left-censoring), between (intervalcensoring), or after the dates when data are collected (right-censoring). For instance, in the case of Kiva lending, we might have had right-censored observations if there were loans in the dataset not yet fully funded by the time data were gathered. Alternatively, left-censoring could have taken place had we had data on loans posted on the Kiva website prior to the starting date of the sample period. Failure to account for such censorings can result in biased and inconsistent estimates of the parameters. However, the censoring is of no concern to our analysis since the Kiva data available to us are for complete transitions only. In other words, the data set includes only those loans that were posted and subsequently funded within the sample period (from 04/17/2006 to 02/19/2008).

36. The reason why these duration data models are formulated in terms of hazard rates (and thus referred to as hazard models) is both historical and technical. For a brief review, see Kiefer (1988).

37. The two most popular ways to analyze the results are by looking either at predicted hazard rates or at predicted duration. An example of when it is of interest to look at the hazard rates is in studies of unemployment. Economists may be interested in looking at how the probability of finding a job and, thus, leaving the "unemployed" state, changes with an individual's personal characteristics. Alternatively, one may analyze effectiveness of public programs for the unemployed by looking at whether they significantly affect participants' probability of finding a job. In this paper, we take another route and analyze the data by looking at the predicted duration and investigating how the latter changes with the per capita income.

38. Unlike in a traditional linear model like Ordinary Least Squares (OLS), hazard models specify the conditional mean of the left-hand side variable as a non-linear function of the parameters. Particularly in the case of our 
study, under the hazard model specification, we assume that $\exp \left(\beta_{1}+\beta_{2} y\right) \cdot \epsilon$, where all the variables $(t, y$, and $\epsilon)$ and parameters ( $\beta$ 's) are as defined earlier.

39. If $f\left(t_{i}\right)$ stands for the probability of the loan funding time taking the value of the $i^{\text {th }}$ observation in our sample, then the joint probability of observing the whole data sample (of $N$ i.i.d. observations) is the product of $N$ individual probabilities, that is, $f\left(t_{1}\right) \cdot f\left(t_{2}\right) \cdot f\left(t_{3}\right) \cdots f\left(t_{N}\right)$. Taking a natural logarithm of this joint probability gives you a sum of logarithms of individual probabilities: $\ln \left[f\left(t_{1}\right)\right]+\ln \left[f\left(t_{0}\right)\right]+\ln \left[f\left(t_{3}\right)\right]+\cdots+\ln \left[f\left(t_{N}\right)\right]$. Having specified $t=\exp \left(\beta_{1}+\beta_{2} y \cdot \epsilon\right)$, this sum of log-probabilities is referred to as the log-likelihood function, where $\beta$ 's are treated as the unknown arguments. Maximizing the function in these unknown parameters gives the estimates of $\beta$ 's that maximize the probability (likelihood) of observing the actual data sample. For an overview of the Maximum Likelihood estimation, see Cameron and Trivedi (2005).

40. This is because the exponential distribution is a special case of the Weibull distribution. That is, the Weibull distribution is identical to the exponential distribution if its shape parameter is equal to unity.

41. The degrees of freedom are the number of data points left free to vary after the estimation of a model. In other words, if $k$ is the number of the estimated parameters and $N$ is the total number of the observations contained in the data sample, then it is said that a model has $(N-k)$ degrees of freedom, that is, a model is estimated using $(N-k)$ independent data points.

42. The fact that there is reason to accept the log-logistic model over its alternatives also gives us reason to believe that the duration dependence for the Kiva loans is non-monotonic and follows an inverted U-shape pattern. In other words, the conditional probability of getting a loan fully funded increases in the first few hours after the project has been posted on the Kiva website as more and more people get to browse it. However, if it is still not funded within the first few hours, the conditional probability of getting the loan funded starts to decrease.

\section{Acknowledgements}

We would like to thank Joshua Knobe, Edouard Machery, David Danks, Susan Wolcott, Jonathan Dang, Ryan Jenkins, and audiences at the Academics Stand Against Poverty Inaugural Conference at Yale University, the University of Buffalo Conference in Experimental Philosophy, and the Metro Experimental Research Group Metaethics Workshop. Nicole Hassoun would also like to thank the Franco-Swedish Program in Philosophy and Economics in Paris, France, and the Centre for Advanced Studies "Justitia Amplificata: Rethinking Justice-Applied and Global," at Goethe University, in Frankfurt, Germany, for support during the project period.

\section{Disclosure statement}

No potential conflict of interest was reported by the authors.

\section{References}

Braybrooke, D. (1987). Meeting needs. Princeton, NJ: Princeton University Press.

Brock, G. (1998). Necessary goods: Our responsibilities to meet others' needs. Lanham, MD: Roman \& Littlefield.

Brock, G. (2005). Needs and global justice. Royal Institute of Philosophy Supplement, 80, 51-72.

Brown, C. (2005). Priority or sufficiency ... or both? Economics and Philosophy, 21, 199-210.

Cameron, C., \& Trivedi, P. (2005). Microeconometrics: Methods and applications. Cambridge: Cambridge University Press. Crisp, R. (2003a). Egalitarianism and compassion. Ethics, 114, 119-126.

Crisp, R. (2003b). Equality, priority and compassion. Ethics, 113, 745-763.

Frankfurt, H. (1987). Equality as a moral ideal. Ethics, 98, 21-43.

Hassoun, N. (2009). Meeting need. Utilitas, 21, 250-275.

Kiefer, N. (1988). Economic duration data and hazard functions. Journal of Economic Literature, 26, 646-679.

Lichtenberg, J. (2004). Absence and the unfond heart: Why people are less giving than they might be. In D. K. Chatterjee (Ed.), The ethics of assistance: Morality and the distant needy (pp. 75-100). Cambridge: Cambridge University Press.

Lumer, C. (2005). Prioritarian welfare functions-An elaboration and justification. In D. Schoch (Ed.), Democracy and welfare. Paderborn: Mentis. Retrieved June 8, 2016, from http://www.lumer.info/wp-content/uploads/2012/04/ A066_Lumer_PrioritarianWelfareFunctions.pdf.

Machery, E., \& Stich, S. (in press). Experimental philosophy of language. In D. Graff \& G. Russell (Eds.), Routledge companion to the philosophy of language. New York: Routledge.

Miller, D. (1999). Principles of social justice. Cambridge, MA: Harvard University Press.

Nahmias, E., Morris, S., Nadelhoffer, T., \& Turner, J. (2006). Is incompatibilism intuitive? Philosophy and Phenomenlogical Research, 73, 28-53.

Nussbaum, M. (2000). Women and human development: The capabilities approach. Cambridge: Cambridge University Press. 
Ogden, T. (2009, October 13). A mostly comprehensive guide to the Kiva and donor illusion debate: Philanthropy action. Retrieved June 27, 2016, from http://philanthropyaction.com/nc/a_mostly_comprehensive_guide_to_the_ kiva_and_donor_illusion_debate/

Parfit, D. (1997). Equality and priority. Ratio, 10, 202-221.

Pogge, T. (2004). Can the capability approach be justified? Philosophical Topics, 30, 167-228.

Rosenberg, R. (2010). Does microcredit really help poor people ? CGAP Focus Note 59. Washington, DC: CGAP. Retrieved from https://www.cgap.org/sites/default/files/CGAP-Focus-Note-Does-Microcredit-Really-Help-PoorPeople-Jan-2010.pdf

Schwitzgebel, E., \& Cushman, F. (2012). Expertise in moral reasoning? Order effects on moral judgment in professional philosophers and non-philosophers. Mind \& Language, 27, 135-153.

Sen, A. (1997). Development as freedom. Oxford: Oxford University Press.

Swain, S., Alexander, J., \& Weinberg, J. (2008). The instability of philosophical intuitions: Running hot and cold on truetemp. Philosophy and Phenomenological Research, 76, 138-155.

Weinberg, J., Gonnerman, C., Buckner, C., \& Alexander, J. (2010). Are philosophers expert intuiters? Philosophical Psychology, 23, 331-355.

Wooldridge, J. (2008). Introductory econometrics: A modern approach (4th ed.). Boston, MA: Cengage.

World Bank Group. (2016). Official development assistance and official aid received (Current US\$). Washington DC: The World Bank Group. Retrieved from http://data.worldbank.org/indicator/DT.ODA.ALLD.CD

Zogheib, B., \& Hlynka, B. (2009). Approximations of the standard normal distribution. Working Paper, WMSR \#09-09. 
Copyright of Philosophical Psychology is the property of Routledge and its content may not be copied or emailed to multiple sites or posted to a listserv without the copyright holder's express written permission. However, users may print, download, or email articles for individual use. 